\title{
Produção científica colaborativa na área da saúde tropical: uma análise da rede de colaboração do Programa de Pós-Graduação em Medicina Tropical da Universidade Federal de Pernambuco
}

\author{
Collaborative scientific production in the tropical health field: an analysis \\ of the collaboration network in the Post-Graduation Program in Tropical \\ Medicine of the Universidade Federal de Pernambuco \\ Producción científica colaborativa en el área de salud tropical: un \\ análisis de la red de colaboración del Programa de Posgrado en Medicina \\ Tropical de la Universidade Federal de Pernambuco
}

Natanael Vitor Sobral | natan_sobral@yahoo.com.br

Universidade Federal da Bahia, Instituto de Ciência da Informação, Programa de Pós-Graduação em Ciência da informação. Salvador, BA, Brasil.

Fábio Mascarenhas e Silva | fabiomascarenhas@yahoo.com.br

Universidade Federal de Pernambuco, Departamento de Ciência da Informação, Programa de Pós-Graduação em Ciência da Informação. Recife, PE, Brasil.

Leilah Santiago Bufrem | santiagobufrem@gmail.com

Universidade Federal de Pernambuco, Departamento de Ciência da Informação, Programa de Pós-Graduação em Ciência da Informação. Recife, PE, Brasil.

Maria Rosângela Cunha Duarte Coêlho | rcoelholika@gmail.com

Universidade Federal de Pernambuco, Departamento de Fisiologia e Farmacologia, Centro de Ciências Biológicas, Programa de Pós-Graduação em Medicina Tropical. Recife, Ciências da Saúde, PE, Brasil. 


\title{
Resumo
}

Este trabalho descreve as motivações e os modos de colaboração científica das redes sociais na área de Saúde Tropical, em estudo sobre a produção de conhecimento de pesquisadores do Programa de PósGraduação em Medicina Tropical da Universidade Federal de Pernambuco (PPGMEDTROP/UFPE), entre 2004 e 2012, considerando sua contribuição significativa para a solução dos problemas da área. Organiza um banco de dados bibliométricos com indicadores científicos para o estudo de coautoria, fundamentado na análise de redes sociais científicas estabelecidas entre os autores. Entrevista nove pesquisadores do Programa para compreender motivações e visualizar as relações de colaboração. Observa a tendência de organização coletiva da Ciência. Destaca como motivações mais importantes dos pesquisadores em prol da colaboração a possibilidade de enfrentar grandes problemas de pesquisa, a obtenção e/ou ampliação de fomento, o processo de validação nos trabalhos realizados em grupo e a possibilidade de avaliar previamente os produtos de pesquisa em relação às instâncias avaliadoras.

Palavras-Chave: Colaboração científica; Redes sociais científicas; Medicina tropical; Saúde tropical; Produção científica; Bibliometria; Motivações para a colaboração.

\begin{abstract}
This paper describes the motivations and forms of scientific collaboration through social networks in the field of tropical health, studying the production of knowledge by researchers from the Post-Graduation Program in Tropical Medicine of the Universidade Federal de Pernambuco (PPGMEDTROP/UFPE), from 2004 to 2012. It considers their significant contribution to the solution of problems in the field. The study organizes a bibliometrical database with scientific indicators for the analysis of co-authorship, based on the analysis of scientific social networks established between authors. The research performed interviews with nine researchers from the Program in order to understand their motivations and visualize their collaboration relationships. It observes the tendency to organize science collectively. The researchers' most relevant motivations to develop collaborations are: the possibility to face large research problems, to obtain and/or enlarge incentives, the process of validation of works performed in group and the possibility to evaluate the research products before the assessment entities.
\end{abstract}

Keywords: Scientific collaboration; Scientific social networks; Tropical medicine; Tropical health; Bibliometrics; Motivations to collaborate.

\section{Resumen}

Este trabajo describe las motivaciones y las prácticas de colaboración científica de las redes sociales en el área de Salud Tropical, en un estudio sobre la producción de conocimiento de los investigadores del Programa de Postgrado en Medicina Tropical de la Universidad Federal de Pernambuco (PPGMEDTROP / UFPE), entre 2004 y 2012, teniendo en cuenta su importante contribución a la solución de los problemas del área. Se organiza una base de datos con indicadores bibliométricos para el estudio de co-autoría, basado en el análisis científico de las redes sociales que se establecen entre los autores. Se entrevista a nueve investigadores del programa para entender las motivaciones y visualizar las relaciones de colaboración. Se observa la tendencia hacia la organización colectiva de la ciencia. Entre las motivaciones fundamentales de los investigadores a favor de la colaboración se destaca la posibilidad de enfrentar los principales problemas de investigación, la adquisición o ampliación del financiamiento, el proceso de validación del trabajo realizado en grupos y la posibilidad de evaluar previamente los productos de investigación.

Palabras clave: Colaboración científica; Redes sociales científicas; Medicina tropical; Salud tropical; Producción científica; Bibliometría; Motivaciones para la colaboración. 
Contribuição dos autores: a contribuição dos autores foi realizada conforme a ordem de autoria.

Declaração de conflito de interesses: não há conflito de interesses.

Fontes de financiamento: este trabalho contou com recursos da Coordenação de Aperfeiçoamento de Pessoal de Nível Superior (CAPES) na forma de bolsa de mestrado.

Histórico do artigo: Submetido: 14.set.2015 | Aceito: 8.mar.2016 | Publicado: 31.mar.2016

Apresentação anterior: Dissertação de mestrado defendida por SOBRAL, N. V. Disponível em: http://www.repositorio.ufpe.br/ bitstream/handle/123456789/13842/Natanael\%20Vitor\%20Sobral\%20v BDTD.pdf?sequence=1\&isAllowed=y

Licença: CC BY-NC atribuição não comercial. Com essa licença é permitido acessar, baixar (download), copiar, imprimir, compartilhar, reutilizar e distribuir os artigos, desde que para uso não comercial e com a citação da fonte, conferindo os devidos créditos de autoria e menção à Reciis. Nesses casos, nenhuma permissão é necessária por parte dos autores ou dos editores.

\section{Introdução}

Nos últimos anos os debates a respeito do caráter social da Ciência ganharam espaços na academia. Como afirma Pielke Junior ${ }^{1}$, discussões sobre o caráter social da Ciência remontam à década de 1930, sendo o tema central da Meeting of the British Science Association (1936) e da American Association for the Advancement of Science (1937). Em 1939 com sua obra clássica 'The social function of science', Bernal2 defendeu a função social da Ciência, em desacordo com o ideal da "ciência pura", pela qual se espera que os cientistas mantenham distância dos assuntos públicos.

O texto seminal 'A Estrutura das Revoluções Científicas' de Thomas Kuhn, publicado originalmente em 1962, trouxe a concepção da Ciência inserida em um arranjo social. Kuhn ${ }^{3}$ fortaleceu a ideia do processo de coletivização da Ciência, acentuado a partir da segunda metade do século XX em razão da composição de grupos de pesquisa e laboratórios no período pós-guerra. Antes disso, a imagem do pesquisador isolado era normal e a solidão fazia parte do cotidiano do cientista, mas o tempo tornou rara a figura do pesquisador autocentrado, que sozinho realizava grandes descobertas. Atualmente se percebe a prevalência do trabalho em colaboração, incentivado pelo princípio do compartilhamento de recursos e redução de custos, o que, intencionalmente ou não, estimula a formação de equipes.

Para a área de saúde, o trabalho em colaboração se apresenta como fundamental, e vem crescendo ao longo dos anos, se tornando predominante nas publicações da área. Entre os anos de 1998 e 2000, os artigos de autoria única eram a maioria, sendo mais de 60\% do quantitativo total. Entre 2004 e 2006, o gráfico inverteu, e os artigos em colaboração já representavam aproximadamente $80 \%$ dos artigos produzidos pela área de saúde ${ }^{4}$.

Diante dos avanços do fenômeno da colaboração na área de saúde, dos benefícios proporcionados pela formulação de redes sociais, e das oportunidades de estreitamento dos cientistas com as demandas sociais, o objetivo deste trabalho é analisar a dinâmica da colaboração científica e as motivações para a formulação de redes sociais na área de Saúde Tropical. Como recorte, definiu-se o Programa de Pós-Graduação em Medicina Tropical da Universidade Federal de Pernambuco (PPGMEDTROP/UFPE) e sua produção do conhecimento no período de 2004 a 2012. Tal escolha considerou a contribuição do mencionado programa para o avanço nos estudos relativos a problemas de saúde pública. 


\section{Referencial teórico}

\section{Análise de Redes Sociais (ARS) na perspectiva da colaboração científica}

A atual configuração do setor acadêmico se pauta na utilização de práticas colaborativas, que se materializam na interação entre os pesquisadores. Isso é percebido nas relações entre pesquisadores de um mesmo grupo de pesquisa (endógenas), nas interações com pesquisadores externos ao grupo de origem (exógenas), e na prática de coautoria, ou seja, nas produções com mais de um autor, expressando vínculos formais entre os pesquisadores, configurando assim, redes sociais científicas.

Delineado desde a revolução industrial como tema de preocupação científica, atualmente o conceito de redes sociais tem originado enfoques e dimensões diversas, atraindo pesquisadores de diferentes áreas, como Antropologia, Sociologia, Economia, Ciências Políticas, Ciência da Informação e Ciências da Comunicação5.

Ao discutir o conceito de redes sociais, percebeu-se que dentre os vários significados atribuídos ao termo, chama a atenção a relação com as Tecnologias da Informação e Comunicação (TIC)6. Sabe-se que o conceito de redes sociais não se restringe às mídias digitais, em verdade abrange as diversas relações existentes na sociedade. Barabási e Castells ${ }^{8}$ têm discutido as redes sociais numa perspectiva considerada social, buscando entender a sociedade e suas dinâmicas, extrapolando o princípio de redes tecnológicas. Estes defendem a ideia de uma sociedade que atua como um ambiente global conectado, concordando com a importância das TIC para a construção deste ambiente, todavia, assumem ênfases diferentes ao discutirem perspectivas de participação. Para Barabási ${ }^{7}$, todos fazem parte de uma grande teia, e nenhum está excluído das conexões que se estabelecem na vida, enquanto Castells ${ }^{8}$ enfatiza a seletividade das redes e as relações de poder como dispositivo de inclusão e exclusão de indivíduos. As duas posições, no entanto, não divergem da definição do termo 'rede social', como o "conjunto de atores e suas ligações"`. Desse modo, assume-se para este artigo a compreensão de rede social como "um grupo de pessoas, de organizações ou de outros relacionamentos, conectados por um conjunto de relações sociais, como as amizades, o trabalho em conjunto ou a simples troca de informações" ${ }^{10}$. Essa definição expressa o elemento essencial de uma rede social, as conexões, que se formam nas relações sociais, unindo os indivíduos e configurando um cenário de interatividade.

É fato que a sociedade encontrou novas formas de organização, superando os antigos modelos que hierarquizavam as pessoas em relações de ordenação e subordinação em que a posse da informação vislumbrava uma perspectiva de poder, em detrimento do seu compartilhamento. Hoje é comum, seja em ambientes acadêmicos, corporativos, pessoais, a perspectiva de redes na qual os atores atuam em colaboração, e o isolamento é cada vez mais raro. Ambientes voltados à troca de informações fazem um maior sentido para nossa forma atual de ser e viver.

São várias as tipologias de redes sociais existentes (acadêmica, institucional, profissional, afetiva). A sua representação gráfica é atribuída a Jacob Moreno (1934), por meio da proposição de um modelo denominado 'sociograma' como uma forma de representação das propriedades formais das configurações sociais; essas poderiam ser representadas em diagramas nos quais os indivíduos eram representados por

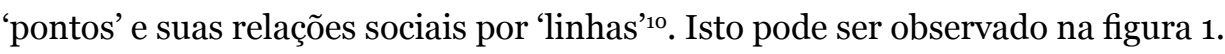

É atribuída a Jacob Levy Moreno (1934) a criação da "Socionomia", que significa o estudo das leis que regem o comportamento social e grupal. 


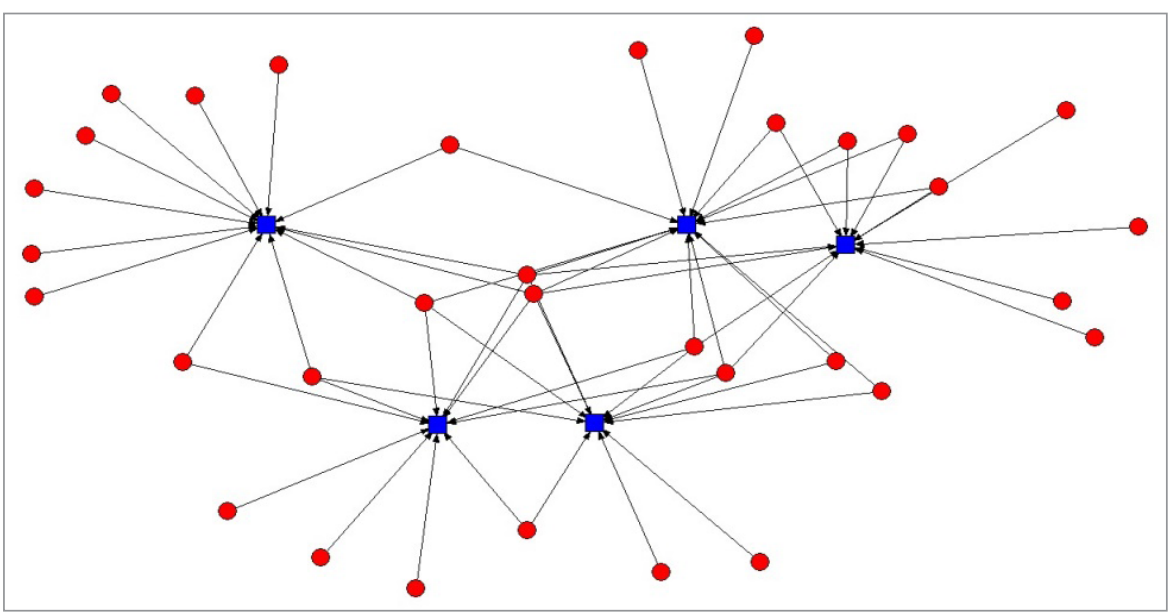

Figura 1: Modelo de Sociograma de colaboração na produção científica elaborado no software UCINET Fonte: Dados da pesquisa, 2015.

Uma das intenções de Moreno $^{11}$ ao estabelecer o sociograma foi criar um instrumento de medição da socialização. Inclusive, Moreno se baseou em Freud e Marx para estudar a realidade socioafetiva dos grupos e observá-los em conjunto e/ou separadamente. Essa configuração gráfica baseada em elementos quantitativos permitiu observar as atrações, as rejeições e os casos de indiferença em grupos sociais ${ }^{12}$. Entretanto, essas avaliações de grupo baseadas em modelos matemáticos requer atenção na contextualização e interpretação dos dados apresentados. Nesses estudos é comum o foco em variáveis metodológicas, comprometendo-se assim o tempo necessário na etapa das análises dos dados, e no entendimento dos valores sociais, que por vezes não se expressam nos dados numéricos.

Ao avançar-se nas variáveis qualitativas existentes nos estudos sociométricos, percebe-se que ainda é incipiente o entendimento das razões que influenciam o modo como os pesquisadores se articulam e constroem suas redes de colaboração científica13. Por esta razão, a temática vem sendo cada vez mais explorada por pesquisadores de distintos campos do conhecimento, e a produção científica nesta temática é crescente.

$\mathrm{Na}$ área de Ciência da Informação, considerando os artigos publicados na Base de Dados Referencial de Periódicos em Ciência da Informação (BRAPCI) ${ }^{\mathrm{ii}}$, constata-se um crescimento da produção científica sobre redes sociais nos últimos anos. A figura 2 refere-se a um levantamento feito na BRAPCI em abril de 2014 como parte deste projeto, que aponta o crescimento do interesse dos pesquisadores pelo tema. A queda apresentada nos últimos dois anos é natural, pois está relacionada ao tempo necessário à indexação dos artigos nas bases de dados.

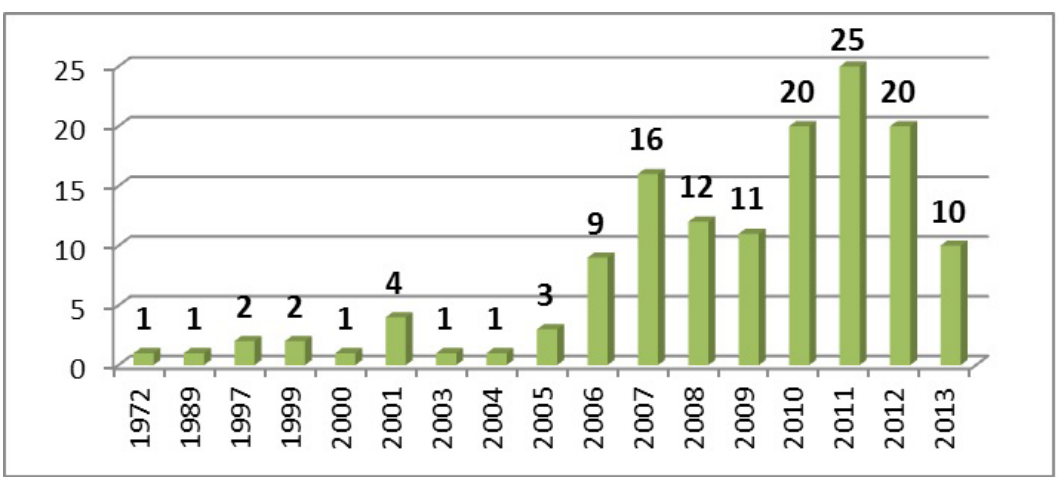

Figura 2 - Crescimento da Produção Científica sobre Redes Sociais na BRAPCI Fonte: Dados da pesquisa, 2015. 
Na figura 3, evidencia-se que a produção em autoria única está cedendo espaço ao longo dos anos às produções em coautoria, reforçando o caráter colaborativo da Ciência e demonstrando que a soma de esforços é uma tendência consolidada na Ciência Moderna em diversos campos do conhecimento.

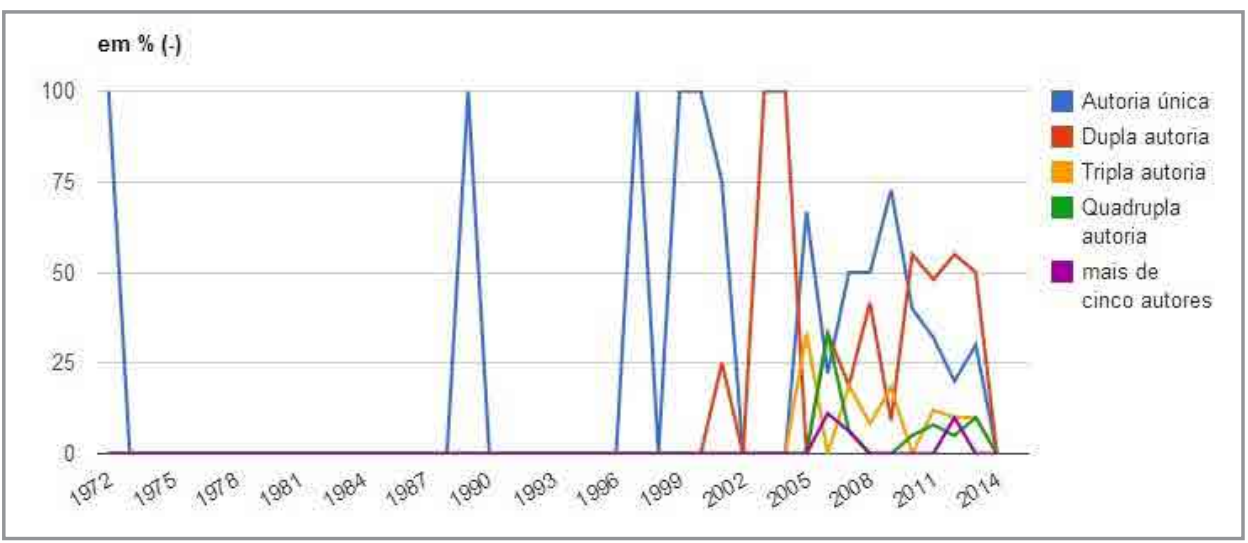

Figura 3 - Crescimento da Produção Científica em coautoria sobre Redes Sociais na BRAPCI Fonte: Dados da pesquisa, 2015.

Na visão de Oliveira e Alves ${ }^{14}$, esse crescimento se dá pela necessidade de melhor conhecer o fenômeno da colaboração, que está cada vez mais presente na cultura científica. Com isto, foi institucionalizado um tipo de estudo voltado para as redes, cujo objetivo seria delinear as relações entre os atores, a fim de retratar, descrever e representar a estrutura de um grupo.

Reconhece-se que estes estudos no âmbito científico se tornaram cada vez mais fundamentais devido às propriedades sociais da Ciência, que tem se organizado numa perspectiva coletiva. Isso é perceptível na concepção dos espaços de compartilhamento científico: veículos de comunicação, eventos, redes sociais eletrônicas científicas, seminários de discussão, reuniões de sociedades científicas, intercâmbios, entre outras. E também, pode ser notado na evolução dos trabalhos em coautoria, que refletem a necessidade que os cientistas têm de interagir, inclusive, sendo esta necessidade, própria de sua natureza humana, que se manifesta independente de estar em meio acadêmico.

Como ferramenta para a análise do conjunto de relações estabelecidas entre pessoas, instituições e outras entidades que convivem em meio social, a técnica ou metodologia de 'Análise de Redes Sociais' (ARS) foi amplamente divulgada por Wasserman e Faust ${ }^{9}$, autores da obra considerada a mais abrangente, didática e rigorosa sobre o tema. Ao discutirem métodos e aplicações da ARS, afirmaram que muitos pesquisadores têm percebido que a perspectiva de rede contribuiu para responder a questões de investigação em ciências sociais e comportamentais, servindo como recurso de interpretação para aspectos do ambiente estrutural político, econômico e social.

Vale ressaltar que um dos fatores que permitiu o avanço do campo de ARS foi o desenvolvimento de recursos metodológicos capazes de auxiliar na construção de representações para as coleções de dados de grandes bases contendo informações sobre a prática científica. Todavia, as formas de representações e os instrumentos tecnológicos são ponte para se atingir uma finalidade maior, que é a interpretação e o entendimento aprofundado das relações estabelecidas entre atores com a finalidade de geração de conhecimento científico.

As ferramentas de ARS vêm sendo utilizadas nos últimos anos, principalmente na perspectiva de avaliação da visibilidade e crescimento da produtividade científica, tendo em vista que estes dois aspectos estão associados aos movimentos de colaboração científica, tornando-se um importante instrumento de gestão. Neste sentido, a coautoria surge como indicador da atividade de colaboração científica, representando assim, 
um elemento adequado para identificar e medir a colaboração, possibilitando trabalhar com universos maiores que conduzem a resultados estatisticamente significantes ${ }^{15}$.

Desse modo, entende-se que a colaboração científica tem um papel fundamental no aumento da produtividade dos pesquisadores. $\mathrm{O}$ ato de colaborar torna o processo de construção da Ciência mais democrático e produtivo, e isto pode ser utilizado estrategicamente pelos países em desenvolvimento para alavancar suas produções e torná-las mais visíveis diante da comunidade acadêmica internacional ${ }^{16}$.

É evidente o papel da ARS como uma técnica explicativa de fenômenos de interação social. Cada movimento descrito na rede representa uma ação social exercida por um ator em conjunto com algum outro. Sendo assim, essa técnica assume uma função que vai além da expressão matemática de um conjunto de relações, servindo principalmente ao propósito de explicar as ligações existentes na rede e as motivações e forças que propiciaram o surgimento das relações.

Sobre o aspecto terminológico, existem termos bastante utilizados na ARS para definir a função ou a ação de cada elemento neste sistema, pelo qual comumente as pessoas são chamadas de atores e as conexões existentes entre elas de ligações ${ }^{17}$. Uma rede é caracterizada por fluxos de informação ${ }^{18}$, o que nos leva a compreender a importância dos estudos de redes sociais no âmbito da CI e o papel da ARS como uma técnica fundamental para o campo de CI.

Diversos autores ${ }^{19-20}$ defendem a ARS como uma ferramenta para o estudo da produção científica, permitindo a identificação de colégios invisíveis, e a observação de aspectos da interdisciplinaridade decorrentes da colaboração de pesquisadores de áreas distintas. Foi identificado que a utilização adequada da bibliometria com a ARS pode contribuir para a medição da colaboração científica entre pesquisadores, instituições e países, tornando visível a frente de pesquisa de dado campo. E isso pode ser realizado por meio da análise de cocitação ou análise de coautoria ${ }^{20}$.

Sobre a aplicação da ARS no âmbito bibliométrico, admite-se que um meio consistente para a realização dos estudos é a utilização da técnica de análise de citações, que toma por base as referências dos textos científicos, buscando identificar relações existentes entre estes e configurando, assim, uma ligação, um elo entre diferentes autores por via do ato de citar.

A aplicação da ARS vem se mostrando bastante útil no que tange à identificação de padrões não detectáveis numa análise simples, entretanto a combinação da ARS com outros métodos e técnicas é essencial para resultados mais satisfatórios, isto pode ser constatado na literatura, principalmente em trabalhos de ordem empírica, em que a ARS foi empregada.

Em um estudo de $2006^{19}$ identificou-se que a aplicação da ARS permitiu uma análise mais aprofundada da colaboração entre pesquisadores, destacando fatos que não seriam detectáveis com o uso de métodos estatísticos tradicionais. Desta forma, argumenta-se que a ARS engloba um conjunto de métodos e técnicas com potencial de contribuição para estudos métricos, especialmente aqueles direcionados à análise da produção científica e das redes de colaboração científica.

\section{Motivações para a colaboração científica na atual configuração da CT\&I}

Na década de 1960, já era alertada a possibilidade do desaparecimento dos artigos de autoria única ${ }^{21}$, em meio ao crescimento da produção científica em coautoria. Por mais que esse pensamento não tenha se confirmado em sua plenitude, é fato a importância da coautoria nos tempos atuais como um comportamento de interação social comum no ambiente acadêmico.

Quando as redes sociais científicas são discutidas na perspectiva da construção do conhecimento, verifica-se que na atualidade o processo de produção do conhecimento científico requer associações, negociações, alinhamentos, estratégias e competências para interligar o maior número de elementos que darão visibilidade ao conhecimento produzido ${ }^{22}$. 
Ressalta-se que além da coautoria, ou produção de conhecimento em conjunto, formas alternativas de relações entre os pesquisadores são possíveis. Embora essa modalidade de colaboração pela coautoria seja a mais utilizada, deve-se ponderar que os pesquisadores trocam e-mails, constroem problemas de pesquisa juntos, fazem leituras, debates, bancas de avaliação, orientações, organizam eventos, e desenvolvem todo um conjunto de produções tecnocientíficas em parceria.

Assim sendo, é evidente o papel das redes sociais científicas como expressão da pluralidade vivenciada no cotidiano acadêmico. Entretanto, vale ressaltar que essas redes de pesquisadores não existem por acaso, alguns fatores podem determinar a seleção dos indivíduos, destacando-se entre eles: compatibilidades entre linhas de pesquisa, participação em mesmo grupo de pesquisa, localidade, atuação profissional na mesma instituição, ou até fatores pessoais, como amizade.

Vanz e Stumpf ${ }^{23}$, baseadas em vários trabalhos ${ }^{15-24-25}$ discutiram a colaboração científica sob o aspecto teórico-conceitual e apresentaram 17 motivações para a colaboração científica entre os pesquisadores (Quadro 1).

Quadro 1: Motivações para a colaboração científica entre os pesquisadores

\begin{tabular}{|l|l|}
\hline \multicolumn{2}{|c|}{ Motivação } \\
\hline 1 & Desejo de aumentar a popularidade científica, a visibilidade e o reconhecimento pessoal. \\
\hline 2 & Aumento da produtividade. \\
\hline 3 & Racionalização do uso da mão-de-obra científica e do tempo dispensado à pesquisa. \\
\hline 4 & Redução da possibilidade de erro. \\
\hline 5 & Obtenção e/ou ampliação de financiamentos, recursos, equipamentos especiais, materiais. \\
\hline 6 & Aumento da especialização na Ciência. \\
\hline 7 & Possibilidade de "ataque" a grandes problemas de pesquisa. \\
\hline 8 & Crescente profissionalização da ciência. \\
\hline 9 & Desejo de aumentar a própria experiência através da experiência de outros cientistas. \\
\hline 10 & Desejo de realizar pesquisa multidisciplinar. \\
\hline 11 & União de forças para evitar a competição. \\
\hline 12 & Treinamento de pesquisadores e orientandos. \\
\hline 13 & Necessidade de opiniões externas para confirmar ou avaliar um problema. \\
\hline 14 & Possibilidade de maior divulgação da pesquisa. \\
\hline 15 & Como forma de manter a concentração e a disciplina na pesquisa até a entrega dos resultados ao resto da equipe. \\
\hline 16 & Compartilhamento do entusiasmo por uma pesquisa com alguém. \\
\hline 17 & Necessidade de trabalhar fisicamente próximo a outros pesquisadores, por amizade e desejo de estar \\
\hline
\end{tabular}

Fonte: Adaptado de Vanz e Stumpf, 2010.

É comum nas relações de colaboração científica haver mais de uma motivação para a realização de um trabalho científico. Dessa forma, as pesquisas sobre motivações para a colaboração devem estabelecer categorias flexíveis que permitam aos entrevistados respostas múltiplas, e também, devem permitir a inclusão de outras categorias além daquelas já descritas na literatura.

Estas motivações, em geral, são mapeadas por meio de questionários ou pela técnica de observação que auxilia a distinguir comportamentos existentes nas relações e os movimentos da dinâmica científica estabelecida no ambiente de análise. Ressalta-se que os estudos sociométricos também ajudam neste mapeamento, sua utilidade é configurada pelo estabelecimento de um quadro inicial do panorama de relações por meio de representações gráficas das redes sociais de pesquisadores.

Na formulação de redes sociais científicas existem diferentes níveis de colaboração (indivíduos, grupos, departamentos, instituições e setores, nas mais diferentes combinações dessas unidades, dentro de uma 
mesma nação ou envolvendo nações diferentes), em geral os prefixos "inter" e "intra" são utilizados para diferenciar estas categorias ${ }^{17}$. Exemplificando esta situação, pode-se imaginar um departamento de uma universidade com dois grupos de pesquisa. Sob o parâmetro grupal, quando os membros do mesmo grupo de pesquisa se relacionam, esta pode ser considerada uma relação intraorganizacional (relação endógena). No caso de estabelecerem ligação com membros do mesmo departamento, porém do outro grupo de pesquisa, esta relação é considerada interorganizacional (relação exógena), pois os agentes da relação são externos ao seu grupo, que é o parâmetro da relação grupal em questão. Este parâmetro pode ser ampliado ou reduzido conforme a necessidade da análise a ser realizada.

No setor acadêmico, estes relacionamentos ocorrem principalmente na busca por novos conhecimentos, e podem trazer como resultados: a economia de tempo, o compartilhamento de recursos materiais, o treinamento de recursos humanos especializados, a mitigação das possibilidades de erro, a troca de experiências e o fomento à interdisciplinaridade. Nas interações interorganizacionais, a similaridade entre as organizações se revela um fator importante, sendo determinada pelos seguintes fatores: proximidade geográfica, compartilhamento de crenças e atitudes, grau de interação, ligações afetivas entre indivíduos das organizações, natureza e status da organização ${ }^{26}$.

\section{Metodologia}

Este estudo, de caráter descritivo, fundamentado em referenciais metodológicos relacionados às análises de contexto e de redes sociais, foi desenvolvido em cinco etapas: a) levantamento de dados sobre os pesquisadores do PPGMEDTROP/UFPE, inclusive suas produções científicas; b) construção de um banco de dados bibliométricos para a geração de indicadores científicos sobre o PPGMEDTROP/UFPE; c) estudo de coautoria para a análise de redes sociais científicas estabelecidas entre os pesquisadores; d) aplicação de entrevistas com perguntas abertas e fechadas junto aos pesquisadores envolvidos no PPGMEDTROP/UFPE para compreender as motivações para a colaboração científica (nove pesquisadores contribuíram com suas respostas); e) realizou-se a análise dos dados coletados na entrevista, relacionando-os com os indicadores obtidos nas etapas anteriores.

Etapa 1: Levantamento de dados: nesta etapa foram identificados os dezenove pesquisadores permanentes vinculados ao PPGMEDTROP/UFPE entre o período de 2004 a 2012 (últimos três triênios de avaliação da CAPES). Para realizar o levantamento da produção bibliográfica dos pesquisadores optouse pela Plataforma Lattes e a ferramenta utilizada para extração dos dados foi o ScriptLattes ${ }^{27}$. Quanto à produção científica analisada, optou-se pelos artigos publicados em periódicos, considerando os resultados encontrados no estudo de Viacava ${ }^{4}$. Neste estudo, ficou evidenciado que $60 \%$ da produção científica da área de Saúde no período de 1998 a 2006 concentrava-se em artigos de periódicos.

Etapa 2: Construção de banco de dados bibliométrico: tratou da conversão dos dados das publicações dos pesquisadores do PPGMEDTROP/UFPE em um formato Bibliométrico com a finalidade de realização de análise de colaboração científica. Para a realização de tal etapa, foi utilizado o arquivo.ris fornecido na extração de dados da ferramenta ScriptLattes. O banco de dados inspirou-se nas experiências de estudos sobre um "corpus" de publicações, a partir da criação de uma base de dados que possibilita tratamento quantificável sobre o corpo da atividade de pesquisa em determinado campo ou área, por exemplo, relações de autoria, institucionais, temáticas, métodos e paradigmas ${ }^{28}$.

Etapa 3: Análise da Colaboração Científica: realizou-se um estudo de coautoria aplicando a técnica de ARS para interpretar os comportamentos dos pesquisadores na prática da colaboração científica. Para a geração das redes sociais científicas foram utilizadas as ferramentas ScriptLattes, UCINET e NetDraw. O primeiro foi aplicado para a identificação das coautorias na Plataforma Lattes do CNPq, o segundo foi 
empregado na representação de uma matriz binária que informou a existência e a ausência de colaboração, e o terceiro serviu ao propósito de representar visualmente os dados no formato de sociograma.

Etapa 4: Instrumentação das Entrevistas: realizaram-se entrevistas fechadas junto aos pesquisadores, buscando-se compreender as principais motivações para a colaboração científica. As perguntas estão disponíveis no apêndice A.

Etapa 5: Análise de Dados: teve por objetivo destacar as percepções mais relevantes e contextualizar as respostas com o cerne do trabalho. Para a apresentação final dos dados optou-se por substituir o nome dos pesquisadores pelos rótulos: ator 1, ator 2, ator 3, e assim sucessivamente.

Em síntese, os procedimentos metodológicos estão representados na figura 5 .

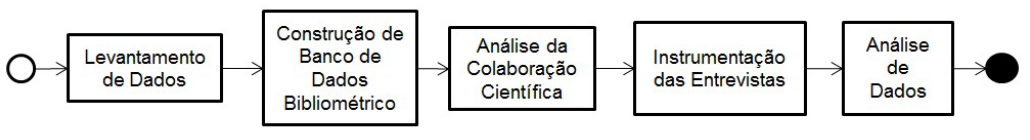

Figura 5 - Fluxo de Procedimentos Metodológicos.

Fonte: Dados da pesquisa, 2015.

\section{Resultados e discussão}

No intuito de entender as motivações para a colaboração científica, realizou-se uma adaptação das 17 categorias de motivações para a colaboração científica ${ }^{29}$, tomando por base estudos anteriores s-24-25-30 $^{15}$ objetivo foi sintetizar as categorias, traduzindo-as para uma linguagem de melhor entendimento para os entrevistados, e desconsiderar questões que seriam irrelevantes para o propósito deste trabalho.

Portanto, estabeleceram-se doze categorias de motivação para a colaboração científica que permitiram identificar os motivos pelo qual os pesquisadores produziam seus artigos em conjunto. No questionário, os pesquisadores poderiam classificar as afirmativas indicadas no quadro 2 a partir dos seguintes estratos: Muito Importante, Razoavelmente Importante, Pouco Importante, Não é Importante (quadro 2).

\section{Quadro 2: Motivações para a colaboração científica}

\begin{tabular}{|l|}
\hline Desejo de aumentar a popularidade científica, a visibilidade e o reconhecimento pessoal. \\
\hline Aumento da produtividade. \\
\hline Redução da possibilidade de erro. \\
\hline Obtenção e/ou ampliação de financiamentos, recursos, equipamentos especiais, materiais. \\
\hline Possibilidade de "ataque" a grandes problemas de pesquisa. \\
\hline Desejo de aumentar a própria experiência através da experiência de outros cientistas. \\
\hline Desejo de realizar pesquisa multidisciplinar. \\
\hline União de forças para evitar a competição. \\
\hline Treinamento de pesquisadores e orientandos. \\
\hline Possibilidade de expandir a pesquisa em outras instituições e países \\
\hline $\begin{array}{l}\text { Necessidade de trabalhar fisicamente próximo a outros pesquisadores, por amizade e desejo de estar } \\
\text { com quem se gosta. }\end{array}$ \\
\hline
\end{tabular}

Fonte: O autor, 2015 (Adaptado de Vanz e Stumpf - 2010). 
Como ponto de partida, procurou-se identificar quais pesquisadores não consideravam a colaboração científica importante, caso houvesse algum pesquisador que concordasse com tal afirmativa, as outras perguntas não seriam realizadas. Todavia, todos os pesquisadores afirmaram que consideram a colaboração científica importante.

Atualmente não se concebe uma ciência sem colaboração, principalmente no campo da saúde, espaço em que o aspecto interdisciplinar tem sido cada vez mais valorizado para a resolução de problemas. Foi identificado na análise da produção científica do PPGMEDTROP/UFPE, que dos 458 artigos de periódicos analisados, apenas dois foram escritos em autoria única, (Cordeiro, M.T. Laboratory diagnosis for dengue e Domingues, A. L. C. Correlação da hidroxiprolina urinária com a carga parasitária na esquistossomose mansônica), o que demonstra a autenticidade na fala dos pesquisadores, que em uníssono, destacaram a importância da colaboração em meio acadêmico.

Com exceção de um pesquisador, todos concordaram com a afirmação de que a formação de pesquisadores e orientandos é uma tarefa muito importante quando se trata do aspecto colaboração científica. Com isto, pôde-se perceber que o desejo de transferir o conhecimento e ampliar as possibilidades de formação de novos cientistas é a força motriz para colaborar e tornar o conhecimento cada vez mais social. Uma das grandes oportunidades de se produzir inovação sustentável no campo de Saúde Tropical é incentivar a entrada de novos pesquisadores qualificados na área, que se interessem pelos problemas sociais da população e proporcionem continuidade aos estudos e à tradição histórica do programa na geração de recursos humanos qualificados que contribuam para solucionar problemas sociais do país, especialmente da região Nordeste.

Outro aspecto ressaltado pelos pesquisadores como fator importante para a colaboração científica foi o desejo de realizar pesquisas multidisciplinares. Somente o esforço em equipe multi ou interdisciplinar é capaz de permitir uma divisão racional do trabalho a partir de pesquisas científicas, cujas exigências por máquinas e equipamentos caros e complexos são impossíveis de ser satisfeitas por um só indivíduo. Em prol da racionalidade, as instituições de fomento, na maioria dos casos, concedem financiamento com maior facilidade às pesquisas realizadas em grupo, valorizando o trabalho em equipe e a soma dos saberes ${ }^{31}$.

Se uma disciplina apresenta excesso de especialização, não se relacionando com outros campos do conhecimento científico, pode-se afirmar que esta é uma disciplina patológica, que reparte o saber, se distanciando da realidade social ${ }^{31}$. No prefácio do livro Interdisciplinaridade e Patologia do Saber ${ }^{31}$, o professor Jayme Salomão afirma que a fragmentação das disciplinas é um fato significativo do desmembramento da realidade humana. Uma ciência em migalhas reflete uma consciência esmigalhada, uma esquizofrenia intelectual, que obsta um conhecimento integral ou totalizante do mundo. Por mais que esta crítica tenha sido direcionada à área de Ciências Humanas, este pensamento também é válido para o campo da Saúde, tendo em vista que a área Médica, como as demais, tem percebido a necessidade de sair de sua clausura para se relacionar com outros campos do conhecimento científico, no intuito de melhor compreender problemas complexos e multifacetados.

É plenamente compreensível e salutar ao campo de Medicina Tropical o estabelecimento de relações multi e interdisciplinares, pois, reduzir a complexidade da área a um paradigma monodisciplinar é negar a complexidade e decretar, a médio e longo prazos, o empobrecimento e a morte consecutiva do campo ${ }^{32}$. Assim, nota-se a relevância das relações multi e interdisciplinares no campo de saúde, principalmente para a evolução do campo de Medicina Tropical, que está extremamente associada aos fatores sociais de ordem econômica e cultural.

Prosseguindo nas reflexões sobre as interações do campo em questão, a figura 6 apresenta a rede de colaboração científica dos pesquisadores do PPGMEDTROP/UFPE. Percebe-se a existência de uma rede densa, na qual somente um pesquisador deixa de apresentar interações de colaboração científica em artigos de periódicos com o grupo. Explica-se esta situação, pelo fato do pesquisador só ter participado do PPGMEDTROP/UFPE como permanente apenas dois anos, e atualmente não faz mais parte do grupo. No mais, notam-se todos engajados na rede. 


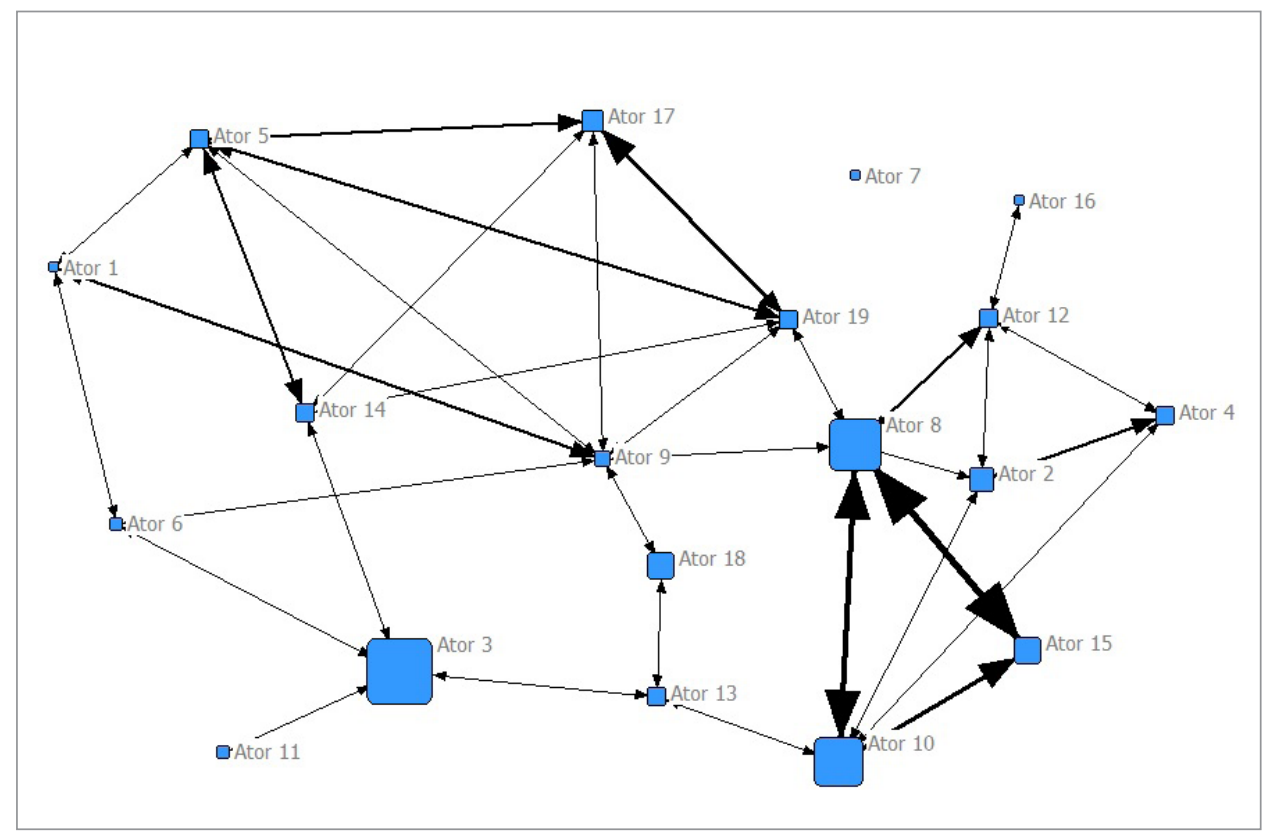

Figura 6: Rede de Colaboração Científica do PPGMEDTROP/UFPE. Fonte: Dados da pesquisa, 2015.

Para a interpretação da figura 6 deve-se compreender que os pesquisadores que aparecem nos nós de maior tamanho são aqueles que têm uma maior produção de artigos, e consequentemente os que aparecem em um nó menor, são os menos representativos neste aspecto. Do mesmo modo, os vínculos de espessura mais larga são aqueles que demonstram um grau de colaboração mais intensa, e vice-versa. Os atores $8,15 \mathrm{e}$ 10 são os que apresentaram um grau de colaboração mais intensa. $O$ assunto principal trabalhado por estes pesquisadores é aids. Em especial, a aids associada às doenças vasculares e à tuberculose.

Como balanço final dos questionários, percebeu-se que as declarações citadas pelos pesquisadores como 'muito importante' em ordem de frequência foram: a) possibilidade de "ataque" a grandes problemas de pesquisa: parece bastante instigante a oportunidade de se envolver com pesquisadores para trabalhar com temas globais e nucleares de grande repercussão; b) obtenção e/ou ampliação de financiamentos, recursos, equipamentos especiais, materiais: sabe-se que na área de saúde o dispêndio de materiais é grande e a oportunidade de dividir equipamentos e obter recursos em parcerias surge como uma interessante opção para que todos os pesquisadores tenham acesso aos recursos de fomento; c) redução da possibilidade de erro: o processo de validação nos trabalhos realizados em grupo é mais intenso, o que permite que o conhecimento construído seja revisado mais de uma vez antes de ser posto à avaliação externa, em síntese, trabalhar em grupo diminui consideravelmente as chances de erro.

Sobre os tópicos menos citados, os principais foram: a) desejo de aumentar a popularidade científica, a visibilidade e o reconhecimento pessoal: os pesquisadores demonstraram pouco interesse de se unir em colaboração com o propósito de erguer uma 'bandeira pessoal', visando tornar popular a sua imagem; b) necessidade de trabalhar fisicamente próximo a outros pesquisadores, por amizade e desejo de estar com quem se gosta: segundo os pesquisadores, os objetivos da colaboração científica estariam desvinculados dos critérios de afetividade; c) união de forças para evitar a competição: conforme constatado anteriormente, segundo os pesquisadores, o objetivo da colaboração não seria um contraponto à competição, mas um fortalecimento à pesquisa multidisciplinar, à formação dos orientandos como pesquisadores e a possibilidade de 'atacar' grandes problemas de pesquisa. 


\section{Considerações finais}

Em geral, os estudos cientométricos se propõem a investigar questões quantitativas da produção científica fazendo uso dos indicadores. Para este trabalho, buscou-se priorizar a dimensão social, admitindo a existência de fenômenos em torno da Ciência que precisam ser investigados numa perspectiva qualitativa, sem abdicar dos instrumentos métricos que favorecem um diagnóstico exploratório do campo do conhecimento científico que se deseja estudar, neste caso, a Medicina Tropical.

Neste contexto, acredita-se ainda mais que o papel do pesquisador é social, e isto se reflete nas redes de colaboração onde estão inseridos, nos temas que selecionam, nas interações com o ambiente externo à academia, e nas atividades de gestão e coordenação ligadas ao universo acadêmico. Quanto mais a atividade grupal se torna comum, mais se percebe a sua importância.

Esta visão colaborativa pôde ser constatada claramente nos resultados da pesquisa, e as principais evidências disto foram: a baixa quantidade de artigos realizados em autoria única, a motivação para a construção de um reconhecimento coletivo em detrimento do sucesso individual, a coletivização dos recursos de laboratório, e principalmente, a oportunidade de resolver grandes problemas de pesquisa a partir da congregação de competências e do trabalho em equipe.

Por fim, a partir de tais resultados, defende-se aqui a visão social da Ciência, preconizando que entre os valores morais que norteiam o trabalho do cientista deve prevalecer o pensamento de colaborar para construir em oposição ao competir para destruir.

\section{Referências}

1. Pielke Junior R. In retrospect: the social function of science. Nature: Books \& Arts Comment [Internet]. 2014 Mar [citado em 1 jun. 2015]; 507(1):427-428. Disponível em: http://sciencepolicy.colorado.edu/ admin/publication files/2014.08.pdf

2. Bernal JD. The social function of Science. 2 ed. London: George Routledge; 1946.

3. Kuhn TS. A estrutura das revoluções científicas. 2 ed. São Paulo: Perspectiva; 1978.

4. Viacava F. Produção científica dos cursos de pós-graduação em saúde coletiva no período 19982006. Ciência \& Saúde Coletiva. 2010 Fev [citado em 1 jun. 2015]; 15(4):1977-1988. Disponível em: http://www.scielo.br/pdf/csc/v15n4/a13v15n4.pdf

5. Marteleto RM. Redes sociais, mediação e apropriação de informações: situando campos, objetos e conceitos na pesquisa em Ciência da Informação. Tendências da Pesquisa Brasileira em Ciência da Informação [Internet]. 2010 Jan/Dez [citado em 1 jun. 2015]; 3(1):27-46. Disponível em: http://inseer. ibict.br/ancib/index.php/tpbci/article/view/26/56

6. Acioli S. Redes sociais e teoria social: revendo os fundamentos do conceito. Informação \& Informação [Internet]. 2007 Dez [citado em 1 jun. 2015]; 12(1):1-12. Disponível em: http://www.uel.br/revistas/ uel/index.php/informacao/article/view/1784

7. Barabási A-L. Linked: a nova ciência dos networks. 1 ed. São Paulo: Leopardo Editora; 2009.

8. Castells M. Sociedade em Rede. 8 ed. São Paulo: Paz e Terra; 2005.

9. Wasserman S, Faust K. Social network analysis: methods and applications. 1 ed. Cambridge: Cambridge University Press; 1994.

10. Braga MJC, Gomes LFAM, Ruediger, MA. Mundos pequenos, produção acadêmica e grafos de colaboração: um estudo de caso dos Enanpads. RAP - Revista de Administração Pública [internet]. 2008 Jan [citado em 1 jun. 2015]; 42 (1): 133-154. Disponível em: http://www.scielo.br/scielo. php?pid=S0034-76122008000100007\&script $=$ sci $\quad$ arttext

11. Moreno JL. Who shall survive?. 1 ed. New York: Beacon Press; 1934.

12. Girard V, Chalvin MJ. Um corpo para compreender e aprender. 1 ed. São Paulo: Edições Loyola; 2001. 
13. Martins DL, Ferreira SMSP. Proposta de metodologia de mapeamento e avaliação da produção científica da Universidade de São Paulo com foco na estrutura e dinâmica de suas redes de colaboração científica: em busca de novos modelos causais. Liinc em Revista [Internet] 2013 Mai [citado em 1 jun. 2015]; 9(1): 181-195. Disponível em: http://revista.ibict.br/liinc/index.php/liinc/article/viewFile/513/394

14. Oliveira EFT, ALVES BH. Os encontros brasileiros de bibliometria e cientometria (EBBCS) em foco: análise da produção, temáticas e relações de coautoria normalizadas. $4^{\circ}$ Encontro Brasileiro de Bibliometria e Cientometria; Recife: UFPE; 2014.

15. Katz JS, Martin BR. What is research collaboration?. Research Policy [Internet]. 1997 Jun [citado em 1 jun. 2015]; 26(1):1-18. Disponível em: http://users.sussex.ac.uk/ sylvank/pubs/Res col9.pdf

16. Lee S, Bozeman B. The impact of research collaboration on scientific productivity. Social Studies of Science. 2005 Out [citado em 5 jun. 2015]; 35(5):673-702.

17. 17. Balancieri R, Bovo AB, Kern VM, Pacheco RCS, Barcia RM. A análise de redes de colaboração científica sob as novas tecnologias de informação e comunicação: um estudo na Plataforma Lattes. Ciência da Informação [Internet]. 2005 Jan [citado em 1 jun. 2015]; 34(1):64-77. Dispoível em: http:// www.scielo.br/scielo.php?script $=$ sci arttext\&pid $=$ S0100-19652005000100008

18. Alejandro VAO, Norman AG. Manual Introdutório à análise de redes sociais: medidas de centralidade [Internet]. Rediris; 1 ed. 2011. Disponível em: http://revista-redes.rediris.es/webredes/talleres/Manual ARS.pdf

19. Silva ABO, Matheus RF, Parreiras FS, Parreiras TAS. Análise de redes sociais como metodologia de apoio para a discussão da interdisciplinaridade na ciência da informação. Ciência da Informação [Internet]. 2006 Jan/Abr [citado em 1 jun. 2015]; 35(1):72-93. Disponível em: http://www.scielo.br/pdf/ci/v35n1/ v35n1a09.pdf

20. Sales R, Guimarães JAC, Oliveira EFT, Bufrem LS. Redes sociais em linguagens documentais: uma análise de coautoria a partir da realidade brasileira. Encontros Bibli [Internet]. 2014 Mar [citado em 1 jun. 2015]; 16(31):1-24. Disponível em: www.brapci.ufpr.br/download.php?dd0=16821

21. Price DJS. A ciência desde a Babilônia. 1 ed. Belo Horizonte: Itatiaia; 1976.

22. Silva EL. Rede científica e a construção do conhecimento. Informação \& Sociedade: estudos [Internet]. 2002 Jan/Abr [citado em 1 jun. 2015]; 12(1):1-17. Disponível em: http://www.ies.ufpb.br/ojs/index. php/ies/article/view/156/150

23. Vanz SAS, Stumpf IRC. Colaboração científica: revisão teórico-conceitual. Perspectivas em Ciência da Informação. 2010 Mai/Ago [citado em 1 jun. 2015];15(2):42-55. Disponível em: http://www.scielo.br/ $\mathrm{pdf} / \mathrm{pci} / \mathrm{v} 15 \mathrm{n} 2 / \mathrm{a} 04 \mathrm{v} 15 \mathrm{n} 2$

24. Beaver DB, Rosen R. Studies in scientific collaboration: part I - the professional origins of scientific coauthorship. Scientometrics. 1978 Jan [citado em 1 jun. 2015]; 1(1): 65-84.

25. Vanz SAS. As redes de colaboração científica no Brasil: 2004-2006. [tese]. Porto Alegre: Universidade Federal do Rio Grande do Sul; 2009. Disponível em: http://www.lume.ufrgs.br/bitstream/ handle/10183/17169/000711634.pdf

26. Scott W. Institutions and organizations. 2 ed. California: Sage Publications; 1995.

27. Mena-Chalco JP, Cesar Junior RM. ScriptLattes: an open-source knowledge extraction system from the Lattes platform. Journal of the Brazilian Computer Society [Internet]. 2009 Dez [citado em 3 abr. 2015]; 4(15): 31-39. Disponível em: http://www.scielo.br/pdf/jbcos/v15n4/04.pdf

28. Falkingham LT, Reeves R. Context analysis: a technique for analysing research in a field, applied to literature on the management of R\&D at the section level. Scientometrics. 1998 Jun [citado em 1 jun. 2015]; 42(2):97-120.

29. Vanz SAS, Stumpf IRC. Colaboração científica: revisão teórico-conceitual. Perspectivas em Ciência da Informação. 2010 Mai/Ago [citado em 1 jun. 2015];15(2):42-55. Disponível em: http://www.scielo.br/ $\mathrm{pdf} / \mathrm{pci} / \mathrm{v} 15 \mathrm{n} 2 / \mathrm{a} 04 \mathrm{v} 15 \mathrm{n} 2$

30. Beaver DB. Reflections on scientific collaboration (and its study): past, present, and future. Scientometrics [Internet]. 2001 Nov [citado em 1 jun. 2015]; 52(3):365-377. Disponível em: http://link. springer.com/article/10.1023\%2FA\%3A1014254214337

31. Japiassu H. Interdisciplinaridade e patologia do saber. 1 ed. Rio de Janeiro: Imago; 1976. 
32. Luz MT. Complexidade do campo da Saúde Coletiva: multidisciplinaridade, interdisciplinaridade, e transdisciplinaridade de saberes e práticas - análise sócio-histórica de uma trajetória paradigmática. Saúde e Sociedade [Internet]. 2009 Jun [citado em 1 jun. 2015]; 18(2):304-311. Disponível em: http:// www.revistas.usp.br/sausoc/article/view/29601/31469

\section{Apêndice}

1 - Indique os motivos pelo qual você considera importante a colaboração científica?

$\mathrm{M}=$ Muito importante

$\mathrm{R}=$ Razoavelmente importante

$\mathrm{P}=$ Pouco importante

$\mathrm{N}$ = Não é importante

Caso responda "não considero importante a colaboração científica" não precisa prosseguir com a resposta.

\begin{tabular}{|l|l|}
\hline & Não considero importante a colaboração científica. \\
\hline & Desejo de aumentar a popularidade científica, a visibilidade e o reconhecimento pessoal. \\
\hline & Aumento da produtividade. \\
\hline & Redução da possibilidade de erro. \\
\hline & Obtenção e/ou ampliação de financiamentos, recursos, equipamentos especiais, materiais. \\
\hline & Possibilidade de "ataque" a grandes problemas de pesquisa. \\
\hline & Desejo de realizar pesquisa multidisciplinar. \\
\hline & União de forças para evitar a competição. \\
\hline & Treinamento de pesquisadores e orientandos. \\
\hline & Possibilidade de expandir a pesquisa em outras instituições e países \\
\hline & $\begin{array}{l}\text { Necessidade de trabalhar fisicamente próximo a outros pesquisadores, por amizade e desejo de estar } \\
\text { com quem se gosta. }\end{array}$ \\
\hline
\end{tabular}

